NBER WORKING PAPER SERIES

\title{
MANDATORY UNBUNDLING AND IRREVERSIBLE INVESTMENT IN TELECOM NETWORKS
}

\author{
Robert S. Pindyck \\ Working Paper 10287 \\ http://www.nber.org/papers/w10287 \\ NATIONAL BUREAU OF ECONOMIC RESEARCH \\ 1050 Massachusetts Avenue \\ Cambridge, MA 02138 \\ February 2004
}

This paper is the result of a study commissioned by Verizon Communications, Inc.. The author thanks Thomas Hazlett of the Manhattan Institute and Coleman Bazelon of Analysis Group, Inc. for assistance with this project. The views expressed herein are those of the authors and not necessarily those of the National Bureau of Economic Research.

(C)2004 by Robert S. Pindyck. All rights reserved. Short sections of text, not to exceed two paragraphs, may be quoted without explicit permission provided that full credit, including (C) notice, is given to the source. 
Mandatory Unbundling and Irreversible Investment in Telecom Networks

Robert S. Pindyck

NBER Working Paper No. 10287

February 2004

JEL No. L0

\section{$\underline{\text { ABSTRACT }}$}

This paper addresses the impact on investment incentives of the network sharing arrangements mandated by the Telecommunications Act of 1996, with a focus on the implications of irreversible investment. Although the goal is to promote competition, the sharing rules now in place reduce incentives to build new networks or upgrade existing ones. Such investments are irreversible - they involve sunk costs. The basic framework adopted by regulators allows entrants to utilize such facilities at prices reflecting what it would cost a new, efficient, large-scale network to be built. Such sharing opportunities are extensive, covering virtually the entire suite of network services provided, and extremely flexible, as the entrant can rent facilities in small increments for short duration, with no long-term contracts required. Because the entrant does not bear the sunk costs, this leads to an asymmetric allocation of risk and return that is not properly accounted for in the pricing of network services, which creates a significant investment disincentive.

Robert S. Pindyck

MIT Sloan School of Management

50 Memorial Drive, E52-450

Cambridge, MA 02142

and NBER

rpindyck@mit.edu 


\section{Introduction}

With the goal of increasing competition, the Telecommunications Act of 1996 (Telecom Act) transferred an important set of property rights from incumbents to entrants. This restructuring allows entrants to use telephone networks according to terms and conditions determined by regulators. Of central importance to this arrangement is that network owners must share their capital with rivals at the option of the rivals, who are free to utilize facilities when they desire to do so, for services of their choosing. They are under no obligation to financially support network investments.

This operational flexibility is of great value to entrants, and is very costly to supply by incumbents. However, the pricing formula used by regulators to set lease rates for capital (i.e., wholesale prices for access to network infrastructure) does not compensate incumbents for these rights. The result is that wholesale network prices are set below competitive market levels, so that incumbents are effectively forced to subsidize entrants. At issue is whether this is efficient, in the sense of promoting investment and enhancing competition in a way that promotes lower prices and higher quality over the long run. I will argue that this pricing formula is not efficient - that it discourages investment by both incumbents and new entrants, and over the long run could threaten the breadth and quality of the telecommunications infrastructure in the United States.

The Telecom Act opened local telecommunications markets to new rivalry, striking down legal entry barriers by pre-empting state-issued franchise monopolies. This succeeded in permitting new competitors to offer services. An interconnection obligation in the Act further guaranteed that these new networks would have an opportunity to compete despite the presence of strong network effects. However, the network sharing rules adopted to further entice entry reduce incentives to invest in network creation by appropriating upside rewards while leaving network owners fully liable for downside losses. Some have argued that this cross-subsidization increases entrants' incentives to invest. $^{2}$ In fact, quite the opposite is most likely.

If promoting entry were costless, it would clearly be desirable to entice more competitors into the market. With the network sharing rules now in place, however, the cost of this entry is to reduce incentives to build new networks or upgrade existing ones. These sharing rules also distort other incentives of both incumbents and entrants that I will not address in this paper. ${ }^{3}$ My concern here is with incentives to build infrastructure

\footnotetext{
${ }^{2}$ See, for example, Affidavit of R. Glenn Hubbard, William H. Lehr, and Robert D. Willig on Behalf of AT\&T Corp., In the Matter of Implementation of the Local Competition Provisions of the Telecommunications Act of 1996, CC Docket No. 96-98, Exhibit C.

${ }^{3}$ For example, Jerry A. Hausman and J. Gregory Sidak, "A Consumer-Welfare Approach to the Mandatory Unbundling of Telecommunications Networks," The Yale Law Journal, Vol. 109:417 (1999), explain that wholesale prices that are artificially low because of regulation make the demand for network sharing more inelastic. Alternatively, Joseph Farrell, "Creating Local Competition," identifies the tension between
} 
in the face of extensive network sharing mandates. When regulation reallocates rights from network owners to other users, it impacts investment incentives to create, expand, or modernize telephone networks. My objective is to clarify these effects.

I focus on the nature of decisions to make irreversible capital investments in telecommunications network infrastructure. Such investments constitute long-term commitments to serve a particular market. A mandate to share this capital with competitive entrants raises important questions: (1) Will payments (for sharing) compensate for the sunk costs that have been made? (2) Will the returns made in "good times" compensate for the lack of compensation expected to be experienced in "bad times." A rational network owner must ask such questions when considering whether to bear the risks associated with irreversible investment. While large outlays are required to bring new technologies and valuable services to the market, shifting claims to the ensuing profits from network builders to others changes economic behavior.

The Telecom Act envisioned a world of independent physical networks competing with each other to provide telecommunications services in local markets. Unbundling was intended to help facilitate entry so this goal could be reached. The intent was not to have permanent regulation, but rather to transition from regulation to free market rivalry. ${ }^{4}$ It is important to determine whether the pathway constructed by regulators is likely to achieve this, or instead will suppress investment and delay the emergence of new technologies and rival systems. The inherent tension between these distinct approaches to competition - creating new networks versus sharing existing facilities with independent suppliers - requires that sharing mandates be evaluated in light of the costs they impose. ${ }^{5}$

universal service obligations and retail rate averaging, on the one hand, and wholesale network sharing prices that are not similarly averaged, on the other. Joseph Farrell, "Creating Local Competition," 49 Federal Communications Law Journal, November, 1996, (available at:

http://law.indiana.edu/fclj/pubs/v49/no1/farrell.html).

4 “The Telecommunications Act is not a rate making statute seeking better regulation. It is a deregulatory statute seeking competition... [T] he Act itself says that its objective is to substitute competition for regulation." Verizon Communications v. FCC, 535 U.S. 467 (2002) (Breyer, concurring in part and dissenting in part, pp. 79-80).

5 "Each unbundling of an element imposes costs of its own, spreading the disincentive to invest in innovation and creating complex issues of managing shared facilities. At the same time... a broad [network sharing] mandate can facilitate competition by eliminating the need for separate construction of facilities where such construction would be wasteful. Justice Breyer concluded that fulfillment of the Act's purposes therefore called for 'balance' between these competing concerns." United States Telecom Association v. Federal Communications Commission (D.C. Cir., No. 00-1012; May 24, 2002), p. 13, footnotes omitted, http://www.fcc.gov/ogc/documents/opinions/2002/00-1012.doc. Justice Breyer's analysis referenced in the opinion appears in Iowa Utilities Board, 525 U.S. pp. 428-29 (Breyer, J., concurring in part and dissenting in part). 


\section{A. Background}

In the United States, each household or business is able to obtain telephone service from one or more suppliers. The traditional operator, until 1996 typically a franchise monopoly, is referred to as an Incumbent Local Exchange Carrier (ILEC). These firms face certain obligations to provide service to retail customers. Pursuant to the 1996 Telecom Act, they also face certain obligations with respect to rival suppliers, which are referred to as Competitive Local Exchange Carriers (CLECs). The Telecom Act requires ILECs to make pieces of their networks available to CLECs, a policy referred to as "unbundling" the local network. The Federal Communications Commission (FCC) has established several unbundled network elements (UNEs) that a competitor can lease individually or collectively. The Telecom Act envisioned CLECs leasing pieces of the local telephone network to complement their own infrastructure investments. For example, a CLEC could install a telephone switch while leasing the copper loop connecting that switch to a customer's premises. The Act also created a retail mechanism that enables a CLEC to resell service delivered over the ILEC's network in neighborhoods where it has yet to construct facilities.

A CLEC and an ILEC might negotiate a price between themselves for the CLEC's use of a UNE. However, if they are unable to negotiate a price (which, given the low regulated prices described below, is usually the case), then the price is determined by regulation. The calculation of the regulated prices for the UNEs is guided by a framework called Total Element Long Run Incremental Costs, or TELRIC. ${ }^{6}$ This approach aims to create a rental rate for each network element that would equal the incremental cost of creating and supplying that leased element if the network owner were designing and constructing a completely new, optimally configured network with state-of-the-art technology.

Unfortunately, TELRIC pricing is inefficient in the sense that it undercompensates ILECs for their investments in infrastructure, and thus is likely to discourage investment. There are two important reasons for this.

First, even if there were no uncertainty over future market conditions, TELRIC prices would still not allow for the full recovery of the ILEC's sunk costs. The reason is that the TELRIC price is based on the current cost (or the expected future cost looking

\footnotetext{
${ }^{6} \mathrm{I}$ am focusing here on wholesale prices. Retail prices for incumbents are usually subject to price-cap or rate of return regulation. A few states, such as Massachusetts, have deregulated or allowed increased pricing flexibility for the rates that incumbent ILECs can charge retail customers.

${ }^{7}$ Two caveats: the design of the optimal network would be constrained by the existing locations of central offices (buildings that house significant electronic equipment) and some portion of common costs are allocated to the individual rate elements. "[T] he regulator must look to what it would cost a hypothetical perfectly efficient firm to supply that element in the future, assuming that the hypothetical firm were to build essentially from scratch a new, perfectly efficient communications network. The only concession to the incumbent's actual network is the presumption that presently existing wire centers - which hold the switching equipment for a local area - will remain in their current locations." Verizon v. FCC, 535 U.S. 467 (2002) (Breyer, J., concurring in part and dissenting in part, p. 3).
} 
two to five years out) of telephone network equipment, rather than the cost that was actually incurred by the ILEC. (The use of current or expected future cost is often referred to as "forward-looking" cost.) Many telecom equipment costs, however, tend to fall over time as a result of technological improvements and increasing competition among suppliers. As a result, the ILEC will receive a price based on an equipment cost that will generally be below the cost it actually incurred. To take a simple example, suppose that two years ago an ILEC bought a switch for \$1 million, and this year the same switch can be purchased for $\$ 800,000$. In this case the TELRIC price for the use of the switch will be based on the current $\$ 800,000$ cost rather than the $\$ 1$ million actually paid, and the ILEC will be unable to recoup the cost of its investment. Looking forward, then, the ILEC knows that even absent risk, a sunk cost investment in new equipment will have a negative NPV, and thus should be avoided. ${ }^{8}$

The second reason that TELRIC pricing under-compensates ILECs for their investments has to do with its treatment of risk. Future market conditions are (and always will be) highly uncertain, so any investment in network infrastructure will yield uncertain returns over the lifetime of the investment. When considering a new investment, the network owner sees the opportunity for positive returns in "good times" as compensation for assuming potential liability for losses should "bad times" prevail. But what about a CLEC that enters the market and considers renting all or part of the network infrastructure? If market conditions are favorable, the CLEC will go ahead and lease the equipment, but if conditions are unfavorable, it will not do so. Thus unlike the ILEC that actually made the capital investment, the CLEC does not bear the burden of the uncertainty - it benefits on the upside, while avoiding the downside. The TELRIC price, however, does not take this into account. As a result, under TELRIC pricing, the ILEC is subsidizing the CLEC by bearing the entire cost of downside exposure to risk. Once again, this discourages capital investment.

Because of the considerable volatility in telecom markets, this second problem with TELRIC pricing is particularly important. If one wants to understand and properly assess TELRIC pricing, it is crucial to understand the full implications of this asymmetric treatment of risk. As explained below, this treatment of risk under TELRIC rules is equivalent to omitting a costly input when calculating the level of compensation for investors in network infrastructure.

\section{B. Network Investments}

If network investments were largely reversible or if there were very little uncertainty over the future returns from such investments, then TELRIC's treatment of risk would not be very important, and could probably be ignored. If network investments were largely reversible, an ILEC could simply "uninvest" if and when market conditions became unfavorable, and would not have to bear the financial consequences of the

\footnotetext{
${ }^{8}$ Of course the TELRIC price is set in state regulatory proceedings and can be influenced by many factors. What is relevant to the above example is that investors anticipate that future TELRIC prices are likely to incorporate capital costs that are below the prices they actually pay to construct network facilities.
} 
unfavorable conditions. (In practice, this would mean selling off the equipment and recovering all or nearly all of the original investment expenditure.) And, of course, if there were very little uncertainty over the future returns from investing, any treatment of risk would be moot to begin with. Note that if either of these conditions held, it would be sufficient to allow us to ignore the issue of risk. The fact is, however, that neither of these conditions holds: Network investments are largely irreversible and there is considerable uncertainty over the returns from those investments.

Why are network investments largely irreversible? For some types of investment, recovery through resale is simply not possible. An example is copper or fiber-optic cable that has been placed underground. Most of the cost of this investment is the cost of putting the cable underground, as opposed to the cable itself, so removing the cable (with the hope of reselling it elsewhere) would not be economical. But what about investments in switches or other equipment that presumably could be uninstalled and resold to some other company? In this case, the problem is that the equipment is industry-specific, and its resale value is tightly connected to economic conditions of the industry. Thus, if conditions turned out to be unfavorable because industry wide conditions were weak, so that the firm wished to "uninvest" by removing and reselling the equipment, it would find that other firms would also want to resell such equipment, and in all likelihood no firm would want to buy the equipment. ${ }^{9}$ In other words, the economic value of the equipment would move up or down along with the economic conditions of the industry, making the investment effectively irreversible. This point is often ignored or misunderstood. Business people, regulators, and even economists will sometimes claim that an investment expenditure is not sunk (i.e., is reversible) as long as the capital could be resold to another firm. At issue is whether it could be resold for something close to the original price at a time when market conditions are so unfavorable that most firms in the industry would also be selling, rather than buying, physical capital.

Why are the returns from network investments highly uncertain? A variety of factors create uncertainty in this industry. On the demand side, although the population (and thus the potential market) tends to grow steadily, the willingness to buy various telecom services - particularly those that tend to generate the most revenue - varies considerably with general economic conditions or even current fashions. In addition, there is competition from close substitutes for land-based telephone service, most notably wireless service but also cable and Internet-based service, and the prices and qualities of these substitutes evolve unpredictably. All of this makes demand volatile and difficult to predict. On the supply side, the very competition induced by regulation - as well as competition that would arise even without regulation - generates uncertainty over the portion of the customer base that the incumbent will be able to service, and the prices that can be charged.

\footnotetext{
${ }^{9}$ To the extent that the fortunes of a particular company are not associated with the fortunes of the industry, this effect is muted. This effect will also be muted for equipment that is not industry specific. For example, cars and trucks could probably be resold to companies in other industries (although at prices below the original purchase prices).
} 
In summary, network investments are largely irreversible and are subject to considerable uncertainty. As will be explained in more detail later, this implies that when a local exchange carrier builds its system, it incurs opportunity costs beyond its actual capital expenditures. The reason is that when the firm makes the investment, it gives up its option to wait to see how uncertainty about markets, costs, and regulations is resolved. Under the FCC's unbundling rules, incumbents are not compensated for this option value, which must be provided to entrants without charge.

\section{Roadmap}

The rest of this paper is organized as follows. Section II provides an overview of the relevant regulations stemming from the Telecom Act, a discussion of the key players in local telecommunications markets, an overview of TELRIC pricing, and an example of how the regulations impact players' costs and behavior. Section III discusses in more detail how TELRIC pricing affects the incentives of ILECs and CLECs. Section IV provides an introduction to the concept of option value, how it arises in the context of irreversible investments under uncertainty, and its application to investments in telecommunications infrastructure. Section V has a more detailed illustration of TELRIC pricing and the disincentives for investment (by both ILECs and CLECs) that it creates. Section VI addresses misconceptions about option value and the cost of capital that have appeared in the regulatory, judicial, and academic literatures. Section VII concludes.

\section{The Regulatory Environment}

Before discussing TELRIC pricing and irreversible investment in detail, it will be useful to briefly summarize the key players, the relevant regulations stemming from the Telecom Act, and the nature of TELRIC pricing itself.

\section{A. The Players}

The incumbent telephone carriers are designated by their prior role in providing telecommunications, typically as franchise monopolies, even as the market evolves past this historical structure. The 1996 Act ended legal barriers to entry. It also placed important mandates on ILECs, which must interconnect with rivals and offer unbundled wholesale access as determined by regulators. While there are hundreds of ILECs, the four largest account for nearly 90 percent of total ILEC lines and 93.8\% of ILEC plant in service. ${ }^{10}$ These are the Regional Bell Operating Companies (RBOCs) - BellSouth, Qwest, SBC and Verizon.

10 Statistics of Communications Common Carriers, Tables 2.8 and 2.13, available at http://www.fcc.gov/Bureaus/Common_Carrier/Reports/FCC-State_Link/SOCC/01socc.pdf and Trends in Telephone Service, Table 7.3, available at http://www.fcc.gov/Bureaus/Common_Carrier/Reports/FCCState_Link/IAD/trend803.pdf. 
CLECs, the competitive entrants, serve retail customers through three main strategies, used alone or in combination. One approach is to enter the market as a pure reseller. Originally, this was done under "resale" as required by the Telecommunications Act. CLECs were given discounts of between $15 \%$ and $25 \%$ when purchasing retail services at wholesale. ${ }^{11}$ This approach has largely been superceded due to more favorable wholesale pricing under UNE-P (for "unbundled network elements platform").

Under UNE-P, the CLEC purchases the entire set of UNEs already preassembled by the ILEC. The CLEC can then rely on an ILEC to provide network services to retail customers, directly supplying only marketing, billing, and some customer service. Done this way, the wholesale discount from retail is typically above $45 \%{ }^{12}$ Pure resellers include Talk America and Z-TEL. Over 11 million (of about 200 million) U.S. telephone lines are provided by UNE-P, with UNE-P lines growing rapidly in 2002 and $2003 .{ }^{13}$ Just over half of these lines are accounted for by AT\&T and MCI, which added local to the long distance telephone service that they provided retail customers. ${ }^{14}$

A second entry strategy used by CLECs combines a subset of UNEs with the CLEC's own capital infrastructure. A typical approach would involve a CLEC renting a local loop, but connecting it to its own (or another CLEC's) switch in the central office, at which point service is provided separately from the ILEC's network. ${ }^{15}$ An example of this type of CLEC is McLeod, which connects its data and voice switches to business customers via local 'last mile' connections owned by the ILEC. ${ }^{16}$

${ }^{11}$ John Hodulik, Batya Levi, Robert Hopper and Rise Barron, "How Much Pain from UNE-P?," UBS Warburg Global Equity Research, August 20, 2002, p. 6.

${ }^{12}$ Ibid., p. 8.

${ }^{13}$ CompTel, "Wholesale Lies: The Truth About RBOC UNE-P Costs,” May 21, 2003.

${ }^{14}$ Association for Local Telecommunications Services, "The State of Local Competition 2003," April 2003.

15 "It is now generally agreed that the most effective method of entering local markets is to lease lines connecting customers to switches and to purchase and install switches. This is being called the 'smart build' model. The lines may be unbundled network loops from an ILEC or lines from another competitor. FirstWorld Communications, Inc. started to install fiber in local markets, but then adopted the 'smart-build' model and 'the economics look a whole lot better,' according to Sheldon Oringer, FirstWorld's president and CEO. 'It doesn't take a whole lot of capital,' he goes on to say, 'to move forward with a switch-based plan." Greg Hallman and Chris McClain, "Real Options and Applications for Telecommunications Deregulation," in James Alleman and Eli Noam, eds., The New Investment Theory of Real Options and Its Implication for Telecommunications Economics (Boston: Kluwer Academic Publishers, 1999, Second Printing 2002), 139-57, p. 143. The market realities have changed substantially since the October 1998 academic conference at which the above paper was given, and FirstWorld has exited the local exchange business. Michael Singer, "EarthLink and Covad Snap Up FirstWorld's DSL Subscriber Base," Siliconvalley. internet.com (July 27, 2001), http://siliconvalley.internet.com/news/article.php/3531_855781.

${ }^{16}$ McLeod USA, Inc. Form 10-K for the Fiscal Year Ending December 31, 2002, p. 3. 
A third entry strategy is to provide phone service without using ILEC facilities, and instead build a competing network infrastructure. Cox is a traditional cable TV operator offering high-speed data services and, in some markets, digital phone service over their fiber-coaxial cable systems. In areas where its telephone service has been available for as long as four years, Cox reports $40 \%$ penetration (i.e., four in ten households that can subscribe do so), an average of 1.4 lines per household, and long distance penetration of 75 percent. ${ }^{17}$ Overall, about 3.0 million households subscribed to cable telephony at year-end 2002. ${ }^{18}$ Given the average penetration rate of $19 \%$ reported by Cox, ${ }^{19}$ about 16 million homes can select local telephone service via their cable TV operator. RCN uses similar hybrid networks to deliver video, voice, and high-speed data (via cable modem) in competition with both cable and telephone service incumbents. The company passes over one million homes, serving about 388,000 video subscribers, 235,000 telephone customers, and 150,000 cable modem subscribers. ${ }^{20}$

\section{B. Unbundled Network Elements (UNEs)}

In implementing the Telecommunications Act's mandate that incumbents share their networks with new rivals, the FCC divided phone networks into seven basic pieces, or "elements." Each of these must be made available to CLECs on terms set by regulators. UNEs include such network building blocks as the local loop (circuits connecting end users to switches located in central offices), switching (routing phone traffic from the 'last mile' connection towards its destination), transport (transmission facilities between central offices), and Network Interface Devices (the box connecting wiring in a customer's premises with the phone network).

Two facets of the unbundling regime are especially important. First, the FCC's rules currently permit UNE-P, allowing entrants to simply resell services without investing in network infrastructure. The second is that the use of such elements, either in combination or separately, allows the entrant much more discretion over services and products it can offer, and when it will offer them.

\footnotetext{
${ }^{17}$ Merrill Lynch, "Cable Telephony Update," February 21, 2003, p. 2; Cox Communications, Presentation to the Deutsche Banc Alex Brown Ninth Annual Media Conference (June 5, 2001), available on www.cox.com/investor.

${ }^{18}$ Federal Communications Commission, "Local Telephone Competition: Status as of December 31, 2002," Table 5 .

${ }^{19}$ Cox Communications, "The Winning Strategy: Positioning Us for Future Growth," Presentation to the Lehman Brothers Conference (May 2003), Slide 5, available on www.cox.com/investor.

${ }^{20}$ RCN Corporation Form 10-Q for the Period Ending March 31, 2003, p. 22.
} 


\section{TELRIC Pricing}

Apart from deciding what elements of the network must be unbundled, the most important aspect of implementing unbundling is determining the prices at which UNEs can be leased - prices that vary by UNE, by area, and over time. Without regulation of these prices, there would be no policy question to resolve: ILECs and CLECs would simply negotiate market-based rates. The motivation for regulation stems from the belief that such negotiation would result in prices inefficiently high, as incumbent operators resisted competition by demanding access fees that reflected their market power.

Under the 1996 Telecommunications Act, as interpreted by the courts, the FCC created a wholesale pricing model which individual state regulatory commissions then utilize to set specific UNE rates. This model is called TELRIC, for total element longrun incremental cost. Under TELRIC, each UNE must be rented by an ILEC to any CLEC at a price that reflects both the incremental costs of providing that specific functionality and some contribution to the common costs of operating a network. A crucial aspect of TELRIC is that these costs are estimated to be those of a hypothetically efficient network built at current prices. (In fact, the assumed costs could be even lower because regulators look at "the forward-looking cost of currently available equipment." That is, costs are based not on the actual experience of the ILEC, nor on the experience of any existing network, but rather on what a state-of-the-art system would now cost to construct. This hypothetical network is assumed to operate at sufficient scale (number of customers served) and scope (number of products offered) such that unit costs are minimized. The entrant, even if inefficient at operating a telecommunications network, may thus avail itself of economies of scale and scope by picking and choosing among the elements, or buying the entire package as a UNE-P.

The details of TELRIC pricing are complicated in that a large number of individual costs must be estimated for specific network configurations. But the basic idea behind the pricing model is straightforward, and can be summarized as follows. Suppose, for example, that at time 0 , a UNE (used in a specific network configuration) has a useful lifetime $T$ and a current purchase cost (net of expected salvage value) $k_{0}$, and that the ILEC weighted-average cost of capital (WACC) is $\rho$. The ILEC would then be "reimbursed" for its capital cost by receiving an annuity payment each year based on this WACC. In other words, on an annual basis it would receive:

$$
A=\frac{\rho(1+\rho)^{T}}{(1+\rho)^{T}-1} k_{0}
$$

\footnotetext{
${ }^{21}$ Federal Communications Commission, Report and Order and Order on Remand and Further Notice of Proposed Rulemaking, In the Matter of Review of the Section 251 Unbundling Obligations of Incumbent Local Exchange Carriers, CC Docket No. 01-338; Implementation of the Local Competition Provisions of the Telecommunications Act of 1996, CC Docket No. 96-98; Deployment of Wireline Services Offering Advanced Telecommunications Capability, CC Docket No. 98-147, paragraph 670.
} 
The total TELRIC price would also include payment for one-time set-up costs and direct and indirect ongoing costs. Thus the total annual rental price would be:

$$
P_{t}=A+\mathrm{DNRC}_{t}+\mathrm{DRC}_{t}+\mathrm{CRC}_{t},
$$

where $\mathrm{DNRC}=$ direct non-recurring costs (e.g., one-time set-up charges);

$\mathrm{DRC}=$ direct recurring costs (e.g., operating expenses tied to the element);

$\mathrm{CRC}=$ common recurring costs (e.g., administrative overhead).

Of course, the CLEC could rent the UNE for only one or two months rather than a year, and the payment would be prorated accordingly.

As a simple example, suppose that an ILEC purchases a switch for $\$ 10,000$ which will serve 100 lines, so that $k_{0}$ is $\$ 100$ per line. Suppose it has a useful life of five years, i.e., $T=5$, and no salvage value. Finally, assume that the firm's cost of capital, $\rho$, is ten percent, that it will cost $\$ 500$ per year to operate the switch, i.e., $\mathrm{DRC}_{t}=\$ 5$ per line, and that $\mathrm{DNRC}_{t}$ and $\mathrm{CRC}_{t}$ are zero. Then, from the formula above, the amortized value of the $\$ 10,000$ investment is $\$ 2,637.98$ per year, or $\$ 26.38$ per line. With direct recurring costs of $\$ 5$, zero salvage value, zero direct non-recurring costs, and zero common recurring costs, the TELRIC price would be $\$ 31.38$ per line per year.

\section{An Entrant's Investment Choices - Wait, Lease, or Build}

A CLEC that is deciding whether to compete with an ILEC can enter the market and provide service in a number of ways, and its decisions will be affected by the regulatory approach embodied in TELRIC pricing of UNEs. In particular, the access rights conveyed to entrants include a range of options and liabilities that the CLEC considers as part of a two-stage entry strategy.

\section{$\underline{\text { STAGE } 1} \quad \underline{\text { STAGE } 2}$}

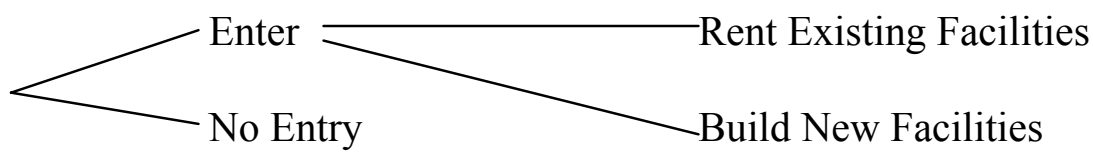

A potential CLEC first considers whether it should become an actual competitor. If it does enter the market, it selects whether to do so by renting existing network facilities, or building its own. (For simplicity, I omit the third path whereon some elements are rented from the ILEC and some are supplied by the CLEC.) The availability of UNEs at TELRIC prices clearly impacts both levels of decision making. Without mandatory network sharing, a firm would confront the same basic choices (enter/no entry, rent/build), but would have to reach a network sharing agreement with an existing 
network were it to rent facilities. ${ }^{22}$ The purpose of unbundling regulation is to lower the effective wholesale price at which such facilities can be accessed.

Focusing solely on direct effects, this regulatory regime heightens incentives for CLECs to enter: Lower input prices increase profits, all else equal. Also, in the second stage, lower rents raise the relative cost of owning rather than leasing. Thus the availability of UNEs at TELRIC prices should (1) induce CLEC entry; and (2) bias CLEC entry toward renting and away from network building (the substitution effect).

But there are also important indirect effects. Entry conditions that discourage CLECs from building networks creates liabilities for all firms - incumbents and new entrants. These firms anticipate that favorable market conditions (e.g., stronger consumer demand than previously expected) will rapidly trigger entry by sharing, which discourages irreversible investment. Because they will compete in the future with CLECs renting ILEC facilities at favorable prices, potential entrants will today anticipate lower future returns than under an alternative regulatory regime. Thus an indirect effect of UNEs at TELRIC prices is that such rules (3) lower irreversible CLEC investment due to anticipated entry via network sharing.

There are other indirect incentive effects, including those flowing from uncertainty introduced by politicization of network access rate-setting. The principle argument for UNEs at TELRIC rates is that entry via renting is highly complementary with future entry by network building, even though the latter may occur much later. Complexities arise that rely on empirical evaluation to sort out. The point here, however, is that mandatory unbundling creates a tension between the use of capital and the creation of capital. This is true even ignoring incumbent network owners.

\section{TELRIC Pricing and "Forward-Looking" Costs}

An important area of confusion about TELRIC pricing is its use of "forwardlooking" costs. The FCC argues that because sunk costs should be ignored by a firm when it makes current output, pricing, or investment decisions, sunk costs should likewise be ignored in the wholesale pricing rule imposed by regulators on network owners. The returns to sunk capital, however, are highly relevant to forward-looking investors, and the income streams from sunk cost investments are the only reason that they are made in the first place. $^{23}$

\footnotetext{
${ }^{22}$ This assumes the existence of the interconnection obligations specified in the Telecom Act.

${ }^{23}$ Alfred Kahn summarized the problem eloquently: "I suppose that I should be flattered by the fact that the Federal Communications Commission cited my Economics of Regulation... six or seven times... I never dreamed, however, in proclaiming that efficient prices should be based on incremental costs, that policymakers would then proceed to ignore the actual incremental costs of the incumbent suppliers and instead adopt as the basis for policy the incremental costs of a hypothetical, most efficient new entrant..." (Alfred Kahn, Whom the Gods Would Destroy, or How Not to Deregulate, AEI-Brookings Joint Center for Policy Studies, Washington, DC, 2001, pp. 3-4; emphasis in original.)
} 


\section{A. A Sunk Cost Fallacy}

The FCC has advanced the idea that wholesale rates should be set on the basis of forward-looking costs, with historical costs disregarded, the intent being to prevent the recovery of costs that were either imprudent or reflective of inefficient "old technology." The FCC argues that with new and improved systems available, competitors should be given access to facilities at their current cost, as if the best systems were deployed. To allow ILECs to recover embedded costs would, as the Supreme Court has put it, promote "some degree of long-run inefficiency." ${ }^{24}$ The idea seems to be that just as decision makers in the marketplace disregard sunk costs, so should regulatory price setters. ${ }^{25}$

This is incorrect. It ignores the basic fact that sunk costs do matter in decisionmaking when those costs have yet to be sunk. The TELRIC pricing rule, by denying investors recovery today of costs previously sunk, deters current investment. The lack of compensation for investments already made cannot deter those past decisions which, by definition, are bygones. But when investors know that new capital outlays will not be recouped, their behavior changes. Investors rationally commit less new capital in anticipation of inadequate returns. The argument that forward-looking costs are the only relevant considerations in an efficient pricing rule confuses the "sunk cost fallacy;" an efficient level of investment requires that the returns to that investment are anticipated to include a payback of sunk costs.

From a public policy perspective sunk costs are hardly irrelevant. If a policy deprives owners of returns from capital already sunk, this alters the perspective of forward-looking investors, who observe a policy change that influences the levels of risk and reward they anticipate in future periods. Investors' estimates of both profits and risk shift in response.

In short, a rule depriving investors of the ability to recoup sunk costs becomes part of the forward-looking analysis for capital not yet sunk. Of course, if there is no concern about creating incentives for new investment, it is reasonable to argue that efficient pricing should be entirely "forward-looking" and sunk costs should indeed be ignored. But creating incentives for new investment is crucial. Capital depreciates and must be maintained or replaced, and efficient new technologies require new investment. The investment needed to adopt new technologies is especially important in local telecommunications networks. If firms considering investing in more modern systems face the constraint that TELRIC pricing will not allow them to recover sunk costs, they simply will not have the incentive to make the investments needed to update and expand telecom networks.

\footnotetext{
${ }^{24}$ Verizon v. U.S., 535 U.S. 467 (2002), p. 45.

${ }^{25}$ The Supreme Court writes: "'Sunk costs' are unrecoverable past costs; practically every other sort of economic 'cost' is forward looking, or can be either historical or forward looking." Ibid., p. 35.
} 
Consider a firm investing in telephone network infrastructure today. The firm could be an incumbent local exchange carrier or a competitive local exchange carrier that will compete with an ILEC regulated under TELRIC rules. To commit to an irreversible investment means risking capital that will be rented in future periods at prices that do not repay today's costs. (In the CLEC case, rival infrastructure will be rented at such rates, making pricing above this level uncompetitive.) TELRIC rates for UNEs are anticipated to decline over time due to improvements in technology. In the short time frame available for analysis of this regulatory structure, UNE rental rates (set by individual states) have tended to decline, as seen in Table 1. Between July and December of 2002, 25 states reduced their UNE rates. ${ }^{26}$ National average UNE-P charges are estimated to have been falling between $15 \%$ and $34 \%$ on an annual basis.

\begin{tabular}{|c|c|c|c|}
\hline \multicolumn{4}{|c|}{ TABle 1. Decline In UNE-P Prices (NATIONAL AVERAGES) } \\
\hline Time Period & $\begin{array}{c}\text { Decline in } \\
\text { UNE-P Rate }\end{array}$ & $\begin{array}{c}\text { Annualized Rate of } \\
\text { Decline }\end{array}$ & Source \\
\hline July to December, 2002 & $7.8 \%$ & $15 \%$ & Gregg 2003 \\
\hline May to August, 2002 & $10 \%$ & $34 \%$ & Kovacs 2002 \\
\hline August to October, 2002 & $5 \%$ & $18 \%$ & Kovacs 2002 \\
\hline
\end{tabular}

Sources: Billy Jack Gregg, "A Survey of Unbundled Network Element Prices in the United States," (Updated January 1, 2003); Anna Maria Kovacs, Kristin Burns and Gregory Vitale, "The Status of 271 and UNE-Platform in the Regional Bells' Territories," Commercial Capital Markets Regulatory Update, November 8, 2002.

From the point of view of forward-looking investors in 2004, this pattern of regulated wholesale rates lowers expected returns from investments in network infrastructure. The treatment of sunk costs under the regulatory pricing rule is hardly irrelevant to investors choosing between alternative projects today.

\section{B. Investment When Costs Decline Over Time}

One might ask why, if improved technologies are available and equipment costs have fallen, should CLECs lease equipment from ILECs at rates based on the oldertechnology and/or higher-cost equipment that the ILEC actually purchased? Indeed, as explained above, the FCC believes that with new and improved systems available, competitors should be given access to facilities at their current cost, as if the best systems had been deployed by the ILEC now, and not at some point in the past. The FCC's view is that to allow the ILEC to recover its actual costs would be inefficient: Pricing should simulate a competitive market, and in a competitive market, equipment that is leased

\footnotetext{
${ }^{26}$ Billy Jack Gregg, "A Survey of Unbundled Network Element Prices in the United States," (Updated January 1, 2003).
} 
should be valued at current incremental cost. ${ }^{27}$ For example, if an ILEC bought a switch two years ago for $\$ 1$ million but that switch could by purchased today for $\$ 800,000$, why shouldn't a CLEC be able to lease the switch based on the current $\$ 800,000$ cost? In a competitive market, wouldn't entry occur based on the $\$ 800,000$ cost?

It is important to understand how and why this is misleading when applied to telecom networks. The textbook model of perfect competition adopted by the FCC assumes that there is free entry and exit, with no sunk costs. In the telecom industry, however, there are very large sunk costs. (In fact, the existence of sunk costs is why TELRIC pricing originated in the first place.) Thus the correct economic model is one in which there is free entry, but entry involves a sunk cost.

Now, consider a market in which there is free entry but at a sunk cost. Suppose, for example, that to enter a firm must buy a machine, which at time $t$ costs an amount $k_{t}$. Furthermore, suppose that this cost has been falling over time, and is expected to continue to fall. For simplicity, we will also assume that marginal operating cost is zero, i.e., the machine cost is the only cost of being in business. The market price at which firms sell their output is $P_{t}$, and it depends on how many firms are operating (or more accurately, total industry capacity). Because the cost of a machine is falling over time, firms in the industry, as well as those contemplating entry, expect that the market price at which they can sell their output will fall over time. How, then, will firms make the decision whether or not to enter the industry?

Each firm invests in machines up to the point that the net present value (NPV) of a machine is just positive. But the NPV must account for the fact that the output price will fall over time as other firms enter at a lower machine cost. Thus the anticipated profit from owning and using the machine in the first year must be higher than it would be were the cost of a machine expected to remain constant. In this way, a firm that buys a machine today can expect to recoup its "losses" from output price declines in the future. If someone were to look at this industry, he or she might think that it was not competitive because the output price today exceeded the amortized price of capital. But of course this just reflects the fact that firms require a positive NPV to invest, and thus must be compensated now for expected entry and price declines in the future. Thus the industry is indeed competitive in the sense that any firm can enter and compete by buying machines. It is this model of competition that UNE pricing should try to simulate.

In the telecom world, CLECs do not have to buy "machines" in order to enter and compete with an ILEC - they can simply lease the ILEC's "machine." At issue is what the lease fee (i.e., the TELRIC price) should be in order to motivate the ILEC (and efficient CLECs) to make further capital investments in the expectation of earning a

\footnotetext{
${ }^{27}$ This view has been put forward by Baumol, Ordover, and Willig (Affidavit of William J. Baumol, Janusz A. Ordover, and Robert D. Willig, In the Matter of Implementation of the Local Competition Provisions of the Telecommunications Act of 1996, CC Docket No. 96-98, Appendix C of AT\&T Comments, May 16, 1996) and Hubbard, Lehr, Ordover and Willig (Affidavit of R. Glenn Hubbard, William H. Lehr, Janusz A. Ordover, and Robert D. Willig on Behalf of AT\&T Corp., In the Matter of Implementation of the Local Competition Provisions of the Telecommunications Act of 1996, CC Docket No. 96-98, Exhibit B, June 10, 1999) among others.
} 
competitive return. There are two possibilities: (1) Set the TELRIC price based on the current capital cost (\$800,000 in our example of an ILEC buying a switch), but allow the ILEC to charge a price for service that is high enough so that it can still expect a positive NPV on its investment. (2) Set the TELRIC price based on the historical capital cost $(\$ 1,000,000$ in our example) that the ILEC actually paid, and do not allow a service price "premium."

In practice, retail price regulation prevents the ILEC from setting a high enough price on its service to earn a "premium" on its current investment. Thus if the ILEC knows that in the future it will be forced to lease its capital at a TELRIC price based on what will then be a lower capital cost, it will calculate that its NPV on the investment is negative, and it will not invest. An NPV of zero (which just gives the ILEC the incentive to invest) requires a TELRIC price based on the higher cost that the ILEC actually paid for its equipment. Given the retail price regulation typically faced by an ILEC, this is the way that regulators can simulate the kind of competitive market that is relevant here.

Note that the discussion above makes no mention of uncertainty over future market conditions. Indeed, uncertainty was assumed away so that we could focus on the problem of expected declines in the cost of equipment. However, uncertainty over future market conditions, and the asymmetric burden of risk that is inherent in TELRIC pricing, is an additional deterrent to investment. This is discussed in the next section. But first, I show analytically why the UNE price should be based on the historical cost paid by the incumbent.

\section{Free Entry with Declining Costs}

Suppose that firms can freely enter an industry simply by buying a machine, and that they can enter either today $(t=0)$ or at a future time $T$. The cost of the machine is the only cost of production, and each machine gives the firm a capacity of one unit of output per period. Suppose that today the cost of the machine is $k_{0}$, but at time $T$ the cost will be $k_{T}<k_{0}$. If today firms knew that there would be no additional entry at time $T$, they would purchase machines up to the point that the NPV of the investment were zero. Thus the market price would be $P_{0}^{N}=r k_{0}$, where $\mathrm{r}$ is the competitive cost of capital (the discount rate), and the superscript $N$ denotes no further entry at $T$.

If instead there will be additional entry at $T$, firms entering today must take this into account. They know that at time $T$ entry will occur up to the point that the NPV of purchasing a machine that costs $k_{T}$ is just zero, so that the price at time $T$ will fall to $P_{T}=$ $r k_{T}$. Thus the NPV of purchasing a machine today is:

$$
\mathrm{NPV}=-k_{0}+\int_{0}^{T} P_{0} e^{-r t} d t+\int_{T}^{\infty} r k_{T} e^{-r t} d t
$$

Firms will invest today up to the point that this NPV is just zero, which implies that the price today (and up until time $T$ ) will be: 


$$
P_{0}^{E}=\frac{r k_{0}-r k_{T} e^{-r T}}{1-e^{-r T}}
$$

where the superscript $E$ denotes that there will be further entry at time $T$.

What is the difference between the initial price when there is further entry and the price when there is not? The difference is given by:

$$
P_{0}^{E}-P_{0}^{N}=\left(k_{0}-k_{T}\right) \frac{r e^{-r T}}{1-e^{-r T}}
$$

Because $k_{T}<k_{0}$, the price when there is entry must be higher than when there is no entry.

Suppose, however, that the initial price is constrained (via retail price regulation) to be at the lower "no entry" level. At time $T$, entrants come in, but rather than buy their own machines, they simply lease the machines owned by the incumbents. If they leased those machines at the rental rate $r k_{0}$, i.e., based on the historical cost that the incumbents paid for the machines, the incumbents would still have an ex post NPV of zero, so that the conditions of a competitive market would prevail. But what if instead the entrants can lease the machines at the lower rental rate $r k_{T}$, i.e., based on the lower "forwardlooking" cost of machines? In that case the incumbents would have an ex post NPV that is negative. In other words, if the incumbents knew in advance that they would have to rent their machines at this lower rate, they would not want to invest in the first place, because investing would yield a below-competitive return on their capital.

This is exactly the problem with the "forward-looking" aspect of TELRIC pricing. When the cost of network equipment has been falling and is expected to keep falling, ILECs will have no incentive to make ongoing investments in their networks. The same disincentives apply to CLECs that might otherwise build their own capital.

\section{Overview of Option Value}

The purpose of this section is to provide a brief overview of the concept of option value, the opportunity cost of making a sunk cost (i.e., irreversible) investment, and the application of these ideas to the Telecom Act and TELRIC pricing. (For a detailed treatment of option value and irreversible investment, see A. Dixit and R. Pindyck, Investment Under Uncertainty, Princeton University Press.)

\section{A. The Option to Invest}

TELRIC pricing is based on a simple investment rule that has been taught widely in business schools, and is the basis for much of neoclassical investment theory in economics: the Net Present Value (NPV) rule. This rule says that a firm should invest in a project if the NPV of the project is positive, i.e., if 


$$
\mathrm{NPV}=-I_{0}-\frac{I_{1}}{(1+\rho)}-\ldots+\frac{\pi_{1}}{(1+\rho)}+\frac{\pi_{2}}{(1+\rho)^{2}}+\ldots>0
$$

where $I_{0}, I_{1}, \ldots$ are investment outlays, $\pi_{1}, \ldots$ are net cash flows arising from the investment, and $\rho$ is the discount rate, usually the WACC. If the investment is completely reversible, or there is no uncertainty over the future cash flows, or this investment is a now-or-never proposition (i.e., there is no possibility of delaying the investment), then this rule is correct. However, if the investment is fully or partly irreversible, there is uncertainty over the cash flows, and the investment could be delayed, the rule is wrong. In particular, the use of this rule does not maximize the firm's value, i.e., the firm would do better using a different rule.

Why is this NPV rule incorrect? Because it makes the wrong comparison - it compares investing today with never investing. The correct comparison is investing today versus waiting, and perhaps (depending on how market conditions turn out) investing at some unspecified time in the future. Put differently, a firm with an opportunity to invest is holding an "option" analogous to a financial call option - it has the right but not the obligation to buy an asset at some future time of its choosing. When a firm makes an irreversible investment expenditure, it exercises its option to invest. It gives up the possibility of waiting for new information to arrive that might affect the desirability or timing of the expenditure; it cannot disinvest should market conditions change adversely. This lost option value is an opportunity cost that must be included as part of the total cost of the investment. As a result, the NPV rule "Invest when the value of a unit of capital is at least as large as its purchase and installation cost" must be modified. The value of the unit must exceed the purchase and installation cost, by an amount equal to the value of keeping the investment option alive.

\section{B. A Simple Example}

A simple example may help to clarify these ideas. ${ }^{28}$ Suppose a firm is considering a network investment that will cost $\$ 8,000$, and will immediately generate annual cash flows that will continue forever. This year, the cash flow will be $\$ 1,000$, but next year, depending on market conditions, it will either increase to $\$ 1,500$ or decrease to $\$ 500$, with equal probability. For simplicity, let us assume that the cash flow will then stay at that level $(\$ 1,500$ or $\$ 500)$ for all future years.

What is the NPV of this investment, assuming we invest immediately? Since the expected value of the cash flow from next year on is $\$ 1,000$, the NPV is:

\footnotetext{
${ }^{28}$ This is a modified version of an example in Chapter 2 of Avinash K. Dixit and Robert S. Pindyck, Investment Under Uncertainty, (Princeton: Princeton University Press; 1994).
} 


$$
\mathrm{NPV}=-8000+\sum_{t=0}^{\infty} \frac{1000}{(1+\rho)^{t}}
$$

where $\rho_{t}$ is the discount rate, i.e., the cost of capital. Assuming that the value of this discount rate is 10 percent, the NPV is equal to $-8000+11,000=\$ 3000$. The NPV is positive, so investment seems warranted. But is it?

Now suppose we wait a year, and then invest only if the annual cash flow goes up to $\$ 1500$. Since the probability of this happening is 0.5 , the NPV as of today is:

$$
\mathrm{NPV}=(0.5)\left[\frac{-8000}{1.1}+\sum_{t=1}^{\infty} \frac{1500}{(1.1)^{t}}\right]=\frac{4250}{1.1}=\$ 3864 \text {. }
$$

By waiting a year before deciding whether to invest, the NPV is $\$ 3864$, whereas it is only $\$ 3000$ if we invest today. Clearly it is better to wait rather than invest now - even though the NPV of investing now is positive. The reason is simple: By waiting, we avoid the consequences of an unfavorable outcome. Had we invested today and had the cash flow dropped to $\$ 500$ per year, the ex post NPV would be

$$
\mathrm{NPV}=-8000+1000+\sum_{t=1}^{\infty} \frac{500}{(1.1)^{t}}=-8000+6000=-\$ 2000
$$

In other words, we would find ourselves losing money. If we wait, on the other hand, we would simply not invest if the cash flow fell to $\$ 500$.

What is the value of having the ability to wait, rather than facing a now-or-never decision? It is just the difference in the two NPVs that we calculated above, i.e., \$3864 $\$ 3000=\$ 864$. This is the value of the "flexibility option." In other words, we should be willing to pay up to $\$ 864$ more for an investment opportunity that is flexible than one that only allows us to invest now.

Given that the NPV of investing today is positive, what are we missing? The problem is that this NPV does not properly account for the full cost of investing today - it only accounts for the direct expenditure of $\$ 8000$. It ignores the opportunity cost of "killing" the firm's option to wait for more information. That opportunity cost is just equal to the value of the option when it is optimally exercised, i.e., when we wait rather than invest immediately. That value is the NPV today when we wait, i.e., it is $\$ 3864$. Thus the true NPV of investing today is $\$ 3000-\$ 3864=-\$ 864$. Hence the NPV of investing today, when properly calculated so as to include opportunity costs, is negative.

This example is a simple one, and thus in some ways unrealistic. Perhaps most important, we assume in the example that all of the uncertainty gets resolved in one year, i.e., next year the annual cash flow will either increase or decrease, but then it will no longer change from this high or low value. In reality, there is always uncertainty over 
future cash flows. ${ }^{29}$ Market conditions are constantly evolving, so that the cash flows from a capital investment will likewise constantly evolve. In such a situation, one must solve an option pricing problem to determine the value of the firm's option to invest and its optimal investment decision. Fortunately, methods developed in finance can be brought to bear, so that solving this problem is not all that difficult. But for the time being we will stick with our extremely simple two-period example.

\section{Application to TELRIC}

This simple example illustrates a major problem with TELRIC pricing. Suppose that an ILEC has just made the $\$ 8000$ investment in network equipment described above. Of course, next year, if the cash flow from the investment falls to $\$ 500$ per year, the ILEC will regret having made the investment rather than waiting (and indeed, as we saw, waiting is optimal), but for purposes of this example we will assume that the ILEC invested nonetheless. Now a CLEC arrives and decides to rent this equipment. How much will the CLEC be charged under TELRIC?

In order to focus on option value and opportunity cost, let us assume that there is no relevant technological change, so that the cost of the network equipment stays at $\$ 8000$. (Recall that another problem with TELRIC is that it is based on forward-looking cost, rather than the cost actually incurred by the ILEC, so that when cost is falling over time, the ILEC will recover less than what it paid to create the infrastructure in question.) Suppose the ILEC's WACC is 10 percent. Because (by assumption) the equipment lasts forever, it would be amortized as a perpetuity, and the CLEC would be charged $(.1)(8000)=\$ 800$ per year.

The problem, of course, is that the $\$ 8000$ base from which the $\$ 800$ annual rental charge is calculated does not fully reflect the ILEC's total cost of its investment. As we saw above, the ILEC also incurred a $\$ 3864$ opportunity cost by investing now and killing its option to wait for additional information. This opportunity cost reflects the fact that if market conditions next year turn out to be adverse (i.e., the cash flow falls to $\$ 500$ ), the ILEC will lose money on its investment. But won't the CLEC also lose money if the cash flow falls next year? No - the CLEC is free to walk away and stop renting the equipment. The CLEC will only continue to rent the equipment if the cash flow increases to $\$ 1500$. Thus the CLEC has a win-win situation. The ILEC, on the other hand, will be left with unprofitable capital should market conditions become adverse.

How much should the CLEC be charged to properly account for the opportunity cost that has been "paid" by the ILEC? The correct capital cost is not $\$ 8000$, but rather $\$ 8000+\$ 3864=\$ 11,864$. Thus the CLEC should pay an annual rental charge of $(0.1)(11,864)=\$ 1,186$. Only then would the ILEC be fully compensated for its total cost

\footnotetext{
${ }^{29}$ In this example, all of the uncertainty is resolved in one year, so if the CLEC enters in year 2 because the cash flow has risen to $\$ 1500$ it will be more profitable for the CLEC to build its own facilities rather than lease the ILEC's capital. If uncertainty about cash flows continued, then the CLEC would find leasing the ILEC's capital more profitable.
} 
of capital investment. Because it is being undercompensated, the ILEC will be discouraged from undertaking further investments.

This example, of course, is highly stylized and oversimplified, with numbers made up for convenience. An important question is how large in practice is the opportunity cost incurred by an ILEC when it invests in network infrastructure, i.e., by how large a percentage does TELRIC undercompensate ILECs? To answer that question requires a more detailed empirical analysis.

\section{TELRIC Pricing: Disincentives Related to Option Value}

The previous section discussed the basic concept of option value and explained why it is missing from TELRIC pricing. In this section, a somewhat more detailed example is presented to further elucidate the sources of option value in a telecommunications network, and to show how it is missing from TELRIC. The example is based on a hypothetical switch that is installed by an ILEC, but may be utilized by a CLEC. I begin by discussing the TELRIC price for this capital investment, and then go on to calculate the option value associated with the ILEC's investment. CLEC entry is then discussed, and it is shown how TELRIC under compensates the ILEC by failing to capture this option value. Finally, I show how the TELRIC price can be corrected to properly account for this option value. To keep this example simple, I ignore other important problems of unbundling at TELRIC prices, such as declining capital costs.

\section{A. The Capital Investment and the TELRIC Price}

Consider an ILEC that will install a new switch, intended to serve any growth in demand above the current baseline level. The switch can serve 40,000 lines, costs $\$ 400,000$, and has a useful life of 4 years. The ILEC knows that demand will grow by 20,000 lines next year (year 1), and will stay at that higher level in year 2. There is uncertainty, however, about what will happen in year 3 . In that year, with equal probability, demand will either grow by 20,000 lines (so that it is 40,000 lines above the original baseline level), or it will fall by 20,000 lines (bringing it back to the baseline level). It will then remain at this level in year 4. If the CLEC enters the market, it will be able to serve the 20,000-line growth in demand (if it occurs) in years 3 and 4 . The ILEC also faces a fixed cost, FC, of $\$ 45,600$ per year. Finally, revenue per line (RPL) from the services of the switch is assumed to be $\$ 7.50$ per year.

To calculate the TELRIC price for this switch, assume that the discount rate is 10 percent per year, and that the only cost associated with the switch is its $\$ 400,000$ purchase price. Thus the annual capital cost for the switch is:

$$
A^{4 y}=\frac{0.1(1+0.1)^{4}}{(1+0.1)^{4}-1} \$ 400,000=\$ 126,188 .
$$


The switch has a capacity of 40,000 lines, but the expected usage of the switch is only 20,000 lines per year. Therefore the per-line TELRIC price for the switch is $P^{\text {TELRIC }}=A^{4 y} / 20,000=\$ 6.3094$.

\section{B. The ILEC's NPV}

Before introducing unbundling and TELRIC pricing, it will be useful to calculate the NPV of the ILEC's investment, assuming that there is no later entry by a CLEC. Given that there is uncertainty over whether demand will increase or decrease in year 3, the ILEC would probably prefer to wait until that uncertainty is resolved before deciding whether to invest. The ILEC is not able to do so, however, because of its duty to serve all customers imposed on it by regulators combined with the fact that it must purchase a 4 year switch. Regulators also set the retail price (in this case the revenue per line, RPL) so that the ILEC does not earn any economic profits on its investment. ${ }^{30}$ In this case, the NPV of the investment in the switch is:

$$
N P V_{0}^{I L E C}=-\frac{400,000}{(1.1)}+\sum_{t=1}^{2} \frac{R P L^{*} 20,000-F C}{(1.1)^{t}}+0.5 * \sum_{t=3}^{4} \frac{R P L^{*} 40,000-F C}{(1.1)^{t}}=\$ 0
$$

The first term on the right-hand side of this equation is the discounted capital cost of the switch. The second term is the present value of the revenue (net of the fixed cost) from the known 20,000 lines of additional demand in years 1 and 2. The third term is the present value of the net revenue from the 40,000 lines of additional demand (the 20,000 from year 2 plus a growth of another 20,000) in years 3 and 4, and is multiplied by 0.5 because there is only a 0.5 probability that demand will indeed grow in year 3 (and a 0.5 probability that demand will fall back to its baseline level so that there is no revenue from the switch in years 3 and 4).

The option value associated with the uncertainty over the growth in demand in years 3 and 4 can be found by recalculating this NPV, but this time giving the ILEC the option of buying two 2-year switches instead of one 4-year switch. I will assume that the purchase price of a 2-year switch is $\$ 219,005$ so that it has the same annualized capital cost and TELRIC price as the 4-year switch. ${ }^{31}$ In this case, the ILEC buys a 2-year switch to serve the additional demand of 20,000 lines in years 1 and 2, but it buys another 2 -year switch in year 3 only if demand increases in that year, which has probability 0.5 of occurring. Because of this flexibility, the ILEC's NPV will now be higher:

\footnotetext{
${ }^{30}$ It is important to be clear about the meaning of zero economic profits. This means that the firm earns an expected risk-adjusted competitive return on its investment. That expected competitive return is the firm's opportunity cost of investing - including it as a cost reduces the firm's profit to zero.

${ }^{31}$ Based on the formula for $A_{t}$ above, the annual capital cost of the 2 -year switch is $\$ 126,188$, as with the 4year switch.
} 
$N P V_{0}^{I L E C}=-\frac{219,005}{(1.1)}+\sum_{t=1}^{2} \frac{R P L^{*} 20,000-F C}{(1.1)^{t}}+0.5 *\left[-\frac{219,005}{(1.1)^{3}}+\sum_{t=3}^{4} \frac{R P L^{*} 40,000-F C}{(1.1)^{t}}\right]=\$ 82,270$

The increase in the NPV - in this case $\$ 82,270$ - is the option value that is lost to the ILEC by being required to commit to the market for 4 years.

\section{ILEC Investment with CLEC Entry}

What happens when unbundling at TELRIC prices is imposed on the existing regulatory regime? To address this question, assume as before that the ILEC must invest in a 4-year switch and stand ready to serve all customers, but that now a CLEC can enter and serve some of those customers, if it is profitable for the CLEC to do so. Specifically, we will assume that the CLEC is able to serve the 20,000-line growth in demand in years 3 and 4, should that growth materialize. As will be clear from this example, the option value of being able to enter and serve this growth in demand is transferred from the ILEC to the CLEC.

Begin with the NPV for the ILEC. In this case, the ILEC spends $\$ 400,000$ on a 4year switch in year 1 , and uses that switch to serve 20,000 customers in years 1 and 2 . If demand falls in year 3 back to its baseline level, the switch then goes unutilized in years 3 and 4. If demand increases by another 20,000 lines, those lines are served by the CLEC, which pays the ILEC the TELRIC price calculated above, and the ILEC continues to serve the first 20,000-line increase above baseline demand. Thus the ILEC's NPV is:

$$
N P V_{0}^{I L E C}=-\frac{400,000}{(1.1)}+\sum_{t=1}^{2} \frac{R P L^{*} 20,000-F C}{(1.1)^{t}}+0.5 *\left[\sum_{t=3}^{4} \frac{R P L^{*} 20,000-F C}{(1.1)^{t}}+\sum_{t=3}^{4} \frac{P^{\text {TELRIC } * 20,000}}{(1.1)^{t}}\right]=-\$ 17,077
$$

Note that the ILEC pays for a four-year switch and gets the revenues from the 20,000 customers in years 1 and 2, but if demand falls in year 3, the ILEC gets no additional revenue from the switch. If demand grows in year 3, the ILEC receives revenue from the customers it continues to have in years 3 and 4 and receives payments from the CLEC for the growth in customers that the CLEC serves. The CLEC's NPV is the expected discounted value of the CLEC's revenues minus its TELRIC payments to the ILEC for the customers added in year 3 .

$$
N P V_{0}^{C L E C}=0.5 *\left[\sum_{t=3}^{4} \frac{\left(R P L-P^{\text {TELRIC }}\right)^{*} 20,000}{(1.1)^{t}}\right]=\$ 17,077
$$

Observe that the CLEC's expected gain is precisely the ILEC's expected loss, i.e., $\$ 17,077$. This transfer from the ILEC to the CLEC results in the ILEC earning less than a competitive return on its investment - a situation that cannot be sustained if we expect the ILEC to willingly invest in the future. 


\section{TELRIC Corrected for Option Value}

The last step in this example is to show how the TELRIC price can be corrected for the ILEC's lost option value. To do this, we find the TELRIC price that makes the ILEC's NPV when there is CLEC entry just equal to zero (instead of the $-\$ 17,077$ calculated above). Thus the corrected TELRIC price satisfies the following NPV equation:

$$
N P V_{0}^{\text {ILEC }}=-\frac{400,000}{(1.1)}+\sum_{t=1}^{2} \frac{R P L * 20,000-F C}{(1.1)^{t}}+0.5 *\left[\sum_{t=3}^{4} \frac{R P L * 20,000-F C}{(1.1)^{t}}+\sum_{t=3}^{4} \frac{\left(P_{\text {Corrected }}^{\text {TELIC }} * 20,000\right.}{(1.1)^{t}}\right]=0 .
$$

The TELRIC price that satisfies this equation is $P_{\text {Corrected }}^{\text {TELIC }}=\$ 7.50$. Using this corrected TELRIC price, the payments from the CLEC compensate the ILEC for the option value of the investment in the switch. Note that the CLEC's NPV is now also equal to zero:

$$
N P V_{0}^{C L E C}=0.5 *\left[\sum_{t=3}^{4} \frac{\left(R P L-P_{\text {Corrected }}^{\text {TELIC }}\right) * 20,000}{(1.1)^{t}}\right]=0 .
$$

With this corrected TELRIC price, both the ILEC and the CLEC are now earning a competitive return. In other words, with this correction, the regulatory regime now comes closer to simulating a competitive market, which is presumably the goal of the regulations in the first place.

\section{Misconceptions}

It has been argued that the TELRIC pricing methodology is efficient despite the problems discussed in this paper. Theories supporting non-remuneration of irreversible investments or ignoring real option values can be constructed, but they rely on special circumstances unrelated to the local telecommunications marketplace. Among these are the arguments that investment disincentives do not matter because local phone networks are already built, that option values are incorporated into the cost of capital used by regulators to establish TELRIC prices, and that investments in local exchange facilities are not irreversible or risky. These arguments are discussed below.

\section{A. The Network Is Already There}

If communications networks were already built and no new investment were needed to maintain or improve them, the disincentives resulting from policies that undercompensate investors might not be of much importance. Owners of existing facilities would suffer economic losses, but consumers would be largely unaffected, because earlier investments in the existing networks cannot be "undone."

The reality of local telecommunications systems, however, is that ongoing investments are necessary just to maintain a given quality of service. Without ongoing capital flows, network functionality will depreciate. From 1990 to 1995, approximately 
\$20 billion in annual capital expenditures was used just to maintain existing Bell (ILEC) networks. (See Figure 1.) With demand for data services (including DSL) beginning to drive new capital expenditures starting around 1996, annual investment grew strongly through 2000. By 2002, real ILEC investment had fallen to about where it was in 1990. Clearly substantial expenditures are needed simply to maintain the existing infrastructure, and further investments are necessary to upgrade systems or to deploy new technologies.

\section{FIGURE 1}

\section{RBOC Capital Expenditures}

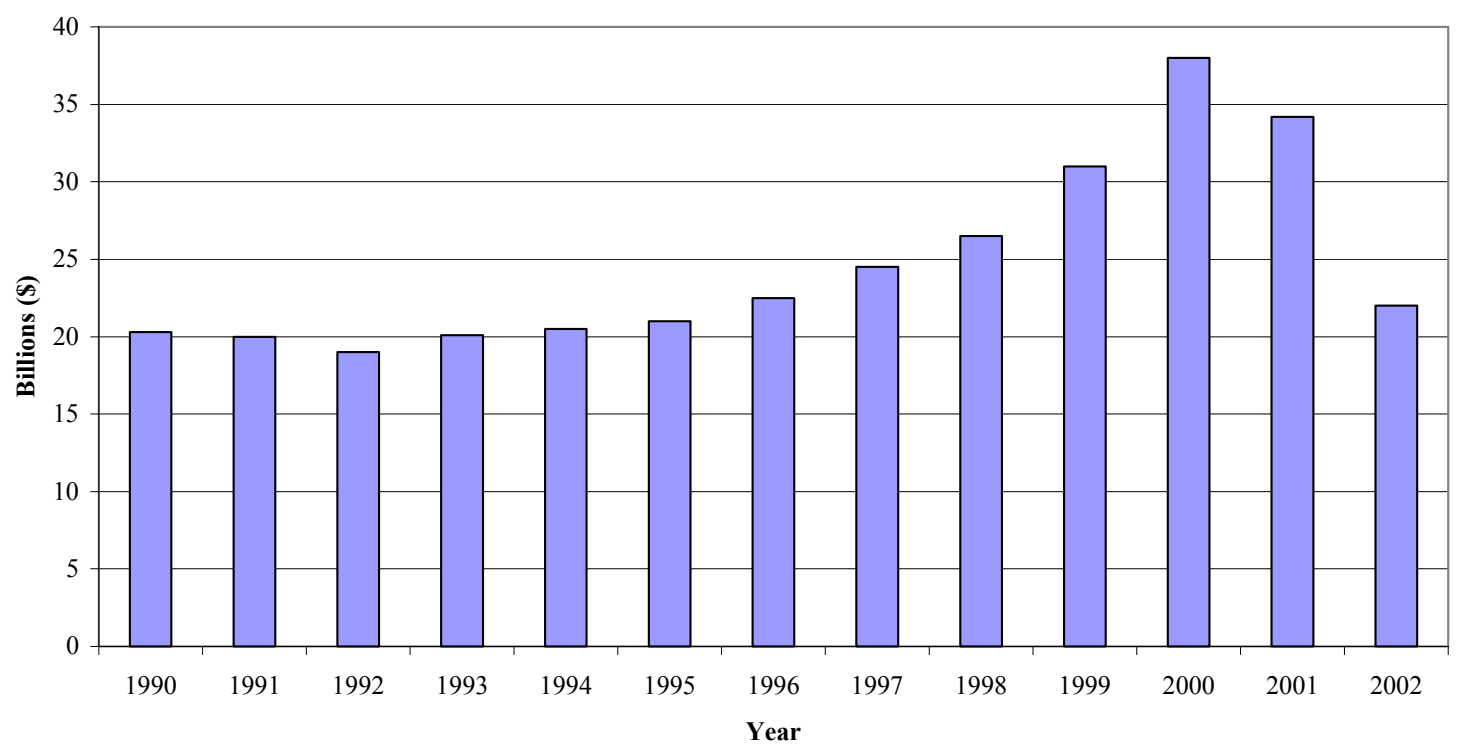

Sources: JP Morgan, as reported in the Association for Local Telecommunications Services, "The State of Local Competition 2003," April 2003, p. 10.

Note: This data excludes expenditures on wireless facilities.

Financial analysts have noted that the replacement level for ILEC capital investment is between fifteen and twenty percent of revenues. ${ }^{32}$ Through 2002, investment levels were in the middle of this range, and were projected to sink to or below the bottom end in $2003 .^{33}$ If new capital flows are constrained, investors will divert resources elsewhere, and services available to consumers will be adversely affected.

\footnotetext{
32 "We think that RBOCs cannot let these ratios decline too much further before they will encounter service-affecting conditions in their networks. We consider 'maintenance' spending levels with capex/revenues in the 15-20\% range." Skyline Marketing Group, "CapEx Report ${ }^{\mathrm{TM}}$ : 2002," (June 2003), http://www.skylinemarketing.com.

${ }^{33}$ Precursor Group, “’Telecom Disconnect': Quality of Bell Free Cash Flow Worsening,” July 21, 2003.
} 


\section{B. Option Value is Already Incorporated in the Cost of Capital}

Some have claimed that the option value discussed earlier is already accounted for in the cost of capital. ${ }^{34}$ In other words, they argue that an input to the calculation of the TELRIC price is the cost of capital, and the cost of capital includes a "premium" that covers the option value inherent in an irreversible investment. This is not true.

The cost of capital that is typically used in the TELRIC price is the ILEC's or a hypothetical firm's weighted average cost of capital (WACC), which is simply an average of its expected return on equity (which can be computed using the Capital Asset Pricing Model, or CAPM) and its cost of debt, with the weights being the relative shares of equity and debt. This WACC does not incorporate any adjustment for option value. To understand why, note that the WACC is simply the firm's opportunity cost of capital. However, it is not the threshold expected return (or hurdle rate) needed to justify an investment. It would be the threshold expected return (or hurdle rate) if the investment in question was reversible, or if the firm had no option to delay investing and thereby wait for more information about market conditions. If, on the other hand, the investment in question is irreversible (as is usually the case in the telecom industry), the hurdle rate must exceed this opportunity cost of capital.

Put differently, if the hurdle rate for an investment is the firm's opportunity cost of capital, then the firm is investing when the NPV of the project is just above zero. But as explained in Section IV of this paper, when the investment is irreversible the NPV must be significantly greater than zero, because the firm is "killing" its option to invest by exercising that option. Thus the firm is incurring an opportunity cost that is missing from the standard NPV calculation. (If the NPV were properly calculated to include this opportunity cost, then the standard NPV rule would apply.) Because of this opportunity cost, an investment is justified only when the standard NPV is significantly greater than zero, so the hurdle rate must be significantly greater than the firm's overall opportunity cost of capital. Equivalently, the firm's opportunity cost of actually investing in new plant or equipment will exceed its overall opportunity cost of capital, i.e., its WACC.

Many (including economists) are confused by this point. Another way to think about it is to remember that the firm can benefit by waiting for information, and thereby avoiding a bad state of the world where an investment yields a negative return. If the firm behaves optimally, it will take this opportunity cost into account. In a competitive market, all firms will take this into account, and on average firms will earn a competitive return on capital - namely the competitive WACC. There is no reward for investing suboptimally, e.g., for ignoring this opportunity cost when determining the hurdle rate for a project. The WACC will prevail on average, but for any specific irreversible investment,

\footnotetext{
34 For example, the FCC claims that all risks are included in the cost of capital. See, Federal Communications Commission, Report and Order and Order on Remand and Further Notice of Proposed Rulemaking, In the Matter of Review of the Section 251 Unbundling Obligations of Incumbent Local Exchange Carriers, CC Docket No. 01-338; Implementation of the Local Competition Provisions of the Telecommunications Act of 1996, CC Docket No. 96-98; Deployment of Wireline Services Offering Advanced Telecommunications Capability, CC Docket No. 98-147, paragraphs 677-684.
} 
the opportunity cost is the WACC plus the cost of exercising the firm's option to invest. Thus the WACC alone does not account for option value.

\section{Most Telecom Investments Are Not Irreversible}

It has also been argued that for the most part, investments in the telecom industry are not irreversible, i.e., do not involve sunk costs. The argument seems to be that much of this capital could be sold to other telecom firms, and thus could be "uninvested."35 This claim suggests a lack of understanding of what a sunk cost entails.

First, in many cases recovery through resale is simply not possible. An example, discussed in the beginning of this paper, is the copper or fiber-optic cable that has been placed underground; most of the cost is the labor for installing the cable, rather than the cable itself, so removing the cable is not economical.

But what about investments in switches or other equipment that could be uninstalled and resold? As explained earlier, the problem is that the equipment is industry-specific, and its resale value is tightly connected to economic conditions of the industry. Thus, if conditions turned out to be unfavorable because industry-wide conditions were weak, so that the firm wished to "uninvest" by removing and reselling the equipment, it would find that other firms would also want to resell such equipment, and no firm would want to buy the equipment. In other words, the economic value of the equipment would move up or down along with the economic conditions of the industry, making the investment effectively irreversible.

Many telecommunications network investments are completely or largely irreversible because physical recovery is uneconomical (as with the copper or fiber-optic cable) and/or the capital itself is industry-specific.

\section{Telecom Investment Returns Are Not Risky}

Option values are important when demand is volatile. If, however, demand for unbundled network elements does not vary much, investment returns will remain fairly constant. Therefore, the premium placed on deferring investments until better information is obtained would be low. In this event, wholesale prices could exclude compensation for real options without substantially distorting investment choices. It has been argued that, as an empirical matter, such conditions hold in this market:

A close examination of the issue of uncertainty in the local telecommunications network reveals that... for most unbundled network elements, there is little demand uncertainty.... For example, the ILEC rarely faces

\footnotetext{
${ }^{35}$ Nicholas Economides, "Real Options and the Costs of the Local Telecommunications Network," in James Alleman and Eli Noam, eds., The New Investment Theory of Real Options and Its Implications for Telecommunications Economics, (Boston: Kluwer; 1999, Second Printing 2002) pp. 207-13.
} 
much uncertainty about local loops that are arguably the most likely to be purchased by competitive local exchange carriers (CLECs). ${ }^{36}$

This argument ignores the fact that the values of assets needed to provide local phone service have proven highly variable. This is evident from the high volatility of equity returns in the communications sector and the fire sale prices for physical assets sold by leading fiber optic manufacturers and switch makers. ${ }^{37}$ The sharp decline in valuations in the sector is, of course, related to the high level of unpredictability: investors would not have sunk so much capital had they possessed better information as to future demands and costs.

Telephone network infrastructure is most economically provided in large, lumpy increments, meaning that large, irreversible investments (efficiently) take place upfront. Over the ensuing years, demand for services, new and old, uses the capacity created. The degree to which customers end up ordering services and how much they will pay to use them is largely indeterminate when the facilities are created. In the traditionally less competitive environment in which POTS (plain old telephone service) was provided by a single franchised operator, risks were lower. But the effects of competition and technological change render that world a bygone era.

Currently, new rivals have the opportunity to take customers away from any operator, and - in the case of an ILEC - can use the operator's own network to serve those customers. Technology has delivered a range of new products to sell customers, but forecasting demand for these services is problematic. It depends not only on how many customers will eventually purchase an existing service, but what complementary innovations are made available by intermediate suppliers - applications developers, equipment makers, content distributors. The "race for bandwidth" has demonstrated the variability in expectations and outcomes. ${ }^{38}$

${ }^{36}$ Nicholas Economides, "Real Options and the Costs of the Local Telecommunications Network," in James Alleman and Eli Noam, eds., The New Investment Theory of Real Options and Its Implications for Telecommunications Economics, (Boston: Kluwer; 1999, Second Printing 2002) pp. 207-13.

${ }^{37}$ A recent article reported on the grim economic landscape dotted with telecommunications infrastructure builders in Denver, Colorado: "[I]t's a little disconcerting to drive out Highway 36, through the 'convergence corridor' that made this town a telecom magnet during the Internet boom, and find the surviving ranchland studded with half-empty office complexes and mostly vacant parking lots... With Qwest now teetering in its downtown high-rise, the shock wave of bankruptcy that's hit American and European Internet carriers is at Denver's door. WorldCom, Global Crossing, KPNQwest, Metromedia Fiber Network, 360netoworks, XO, Williams Communications - in two and a half years these companies have incinerated an astonishing $\$ 69$ billion in shareholder equity..." Frank Rose, "Surviving the FiberOptic Fire Sale," Wired (November 2002), http://www.wired.com/wired/archive/10.11/fiber_optic_pr.html.

${ }^{38}$ Many have noted that investment conditions have changed markedly in telecommunications. Recent experience shows that returns from long-term capital investments are highly variable, distinct from the pattern in previous generations when the pace of technological change was more measured and competitive pressures less intense. See, for example, the papers presented at the conference at Columbia University (May 30, 2002), "The New Telecommunications Industry and Financial Markets: From Utility to Volatility," http://www.citi.columbia.edu/conferences/volatility.htm. 


\section{Conclusions}

The Telecommunications Act sought to promote competition among networks, which could produce benefits both in the delivery of new services and in the more efficient delivery of existing services. But ultimately these benefits will require substantial investment in technologies where demand is highly uncertain. At issue is whether the current regulatory structure creates the incentives for such investment. I have argued in this paper that it does not. By making incumbents' network investments available to competitors at rates that do not fully compensate the incumbents for the opportunity costs of their investments, further investment is deterred.

The importance of investment incentives seems to have been better recognized in other areas of telecom regulation. When dealing with new markets, such as broadband, unbundling rules tend to be much more limited. In cable modem service, for example, the Federal Communications Commission has repeatedly declined to attach "open access" obligations, giving cable system operators an unfettered (and unshared) right to vertically integrate into Internet services. The rationale has not been that market power is unimportant, but that encouraging the deployment of new technology takes precedence. Consumers are not well served by "protections" that eliminate productive investments, and so limit service. But this applies to existing telephone networks as well. Indeed, the creation of new competitive systems is undermined when CLECs, like ILECs, have little incentive to invest.

The undercompensation of ILECs by TELRIC pricing might suggest that a simple transfer has been created. After all, what is wrong with subsidizing entry if that is what is needed to jump-start competition? The problem is that in the long run there are no gains to CLECs from under-pricing UNEs. That is because the retail-wholesale price margin, a form of regulatory arbitrage, is available to all CLECs, and to all which desire to be CLECs. With open entry, a positive present value of the pure resale model cannot be sustained. $^{39}$ Hence the under-pricing produces investment disincentives without offsetting benefits. This would be a problem in any sector, but is particularly costly when it involves such large and important infrastructure.

Striking down barriers which stifle competition is not, when properly executed, controversial. The Telecommunications Act's pre-emption of state telephone franchising laws that sheltered de facto monopolies was straightforward, and hundreds of CLECs were soon certified by utility commissions. Cable telephony and wireless networks are today routinely interconnecting with ILEC systems. They offer close substitutes that are replacing ILEC lines and, more importantly, taking substantial shares of local and long distance revenues. In the $14 \%$ of U.S. homes where a cable system already offers phone

\footnotetext{
${ }^{39}$ Thomas W. Hazlett, "The Irony of Regulated Competition in Telecommunications," Columbia Science \& Technology Law Review (forthcoming 2003); http://www.manhattan-institute.org/MI_TWH_paper.pdf.
} 
service, or the much higher percentage where one or more of the six national wireless carriers offer coverage, full-blown network rivalry has already emerged.

Policies that recognize and account for investment incentives are better able to insure the continued health of existing networks and the growth of new ones. Current network sharing rules in telecommunications ignore the importance of the irreversibility of capital investment. As discussed in this paper, this reduces the incentive to invest, which in the long run is welfare reducing for the consumers of telecom services. 